\title{
Undernutrition and associated factors among adult HIV/AIDS patients receiving antiretroviral therapy in eastern zone of Tigray, Northern Ethiopia: a cross-sectional study
}

Tsegu Hailu Gebru* (1D, Haftea Hagos Mekonen ${ }^{\dagger}$ and Kbrom Gemechu Kiros ${ }^{\dagger}$

\begin{abstract}
Background: Undernutrition and HIV/AIDS are highly prevalent in sub-Saharan Africa, Ethiopia inclusive as linked in a vicious cycle. Thus, several studies have documented that undernutrition among HIV/AIDS patients increases the risk of mortality, decrease survival rates, affect the overall clinical outcome and quality of life.

Despite this fact, information about the burden of undernutrition and associated factors among adults receiving antiretroviral therapy is lacking in the particular study area. Hence, this study aimed to examine the prevalence of undernutrition and associated factors among adult HIV/AIADS patients receiving antiretroviral therapy patients in Eastern Zone of Tigray, Northern Ethiopia.
\end{abstract}

Methods: A cross-sectional research design was adopted in data collection while systematic sampling technique was employed to sample and select the study subjects. A structured questionnaire was used to collect information from 394 study subjects through face to face method.

Also, data on demographics, laboratory and anthropometric variables were collected from each selected patients sampled. The data collected were entered and analyzed using SPSS version 22.. Bivariate and multivariable logistic regression analysis with 95\% confidence interval were used to find factors associated with undernutrition. The adjusted odds ratio was calculated to show the strength of the association. Variables with $p$-value of $<0.05$ were considered statically significant.

Results: The mean age of the respondents was 41 ( \pm 10). Out of 394 study respondents, about $42.9 \%$ of them were undernourished (95\% Cl: 37.8-47.7).

Respondents who had CD4+ count less than 200 cells/ $\mu \mathrm{l}(\mathrm{AOR}=1.84 ; 95 \% \mathrm{Cl}: 1-3.36)$, being advanced clinical staging $(\mathrm{AOR}=3.6 ; 95 \% \mathrm{Cl}: 2.11-6.18)$, and not taking co-trimoxazole preventive therapy ( $\mathrm{AOR}=2.38 ; 95 \% \mathrm{Cl}: 1.21-4.6)$ were independently associated with undernutrition.

(Continued on next page)

\footnotetext{
* Correspondence: tsegshhailu16@gmail.com

${ }^{+}$Haftea Hagos Mekonen and Kbrom Gemechu Kiros contributed equally to this work.

Department of Nursing, Adigrat University, Adigrat, Tigray, Ethiopia
}

(c) The Author(s). 2020 Open Access This article is licensed under a Creative Commons Attribution 4.0 International License, which permits use, sharing, adaptation, distribution and reproduction in any medium or format, as long as you give appropriate credit to the original author(s) and the source, provide a link to the Creative Commons licence, and indicate if changes were made. The images or other third party material in this article are included in the article's Creative Commons licence, unless indicated otherwise in a credit line to the material. If material is not included in the article's Creative Commons licence and your intended use is not permitted by statutory regulation or exceeds the permitted use, you will need to obtain permission directly from the copyright holder. To view a copy of this licence, visit http://creativecommons.org/licenses/by/4.0/ The Creative Commons Public Domain Dedication waiver (http://creativecommons.org/publicdomain/zero/1.0/) applies to the data made available in this article, unless otherwise stated in a credit line to the data. 


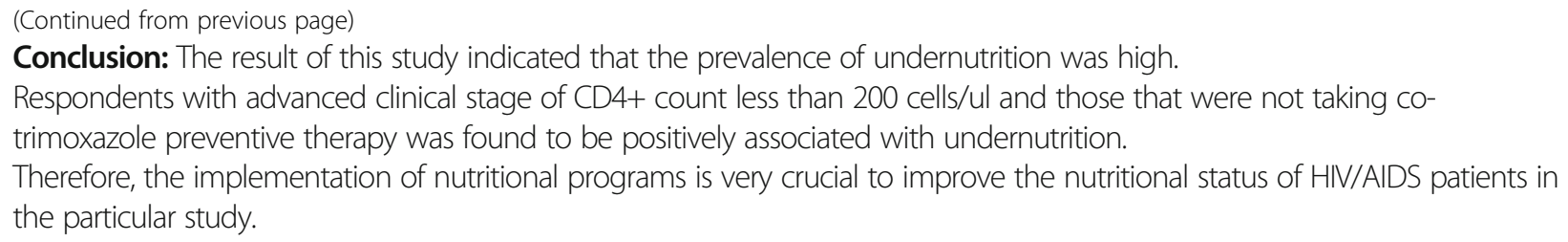

Keywords: Undernutrition, HIV/AIDS, Antiretroviral therapy, Tigray, Ethiopia

\section{Background}

Human Immunodeficiency Virus (HIV) and AIDS remained a significant problem health burden particularly in developing countries.

By the end of 2016, about 34.5 million adults were living with HIV and an estimated 1 million patients died due to Acquired Immunodeficiency Syndrome (AIDS) related conditions [1]. Around $64 \%$ of the global HIV positive population are found in Sub-Saharan Africa (SSA) [1]. Globally, over 800 million people remain chronically undernourished and the HIV epidemic largely overlaps with populations already suffering from low diet quality and quantity [2].

Undernutrition is the predominant problem for HIV infected patients. It creates a vicious cycle which may catalyze progression from HIV infection to AIDS [3]. Poor nutrition resulting in weight loss, muscle wasting, weakness, nutrient deficiencies then it leads impaired immune system (poor ability to fight HIV and other infections, increased oxidative stress, increased vulnerability to infections). Hence, increased HIV replication, hastened disease progression and increased morbidity, then it leads to increased nutritional needs, and increased loss of nutrients. On the other hand, adequate dietary intake enhances the therapeutic effect of medicines, boosts the immune system (thus helping to fight against the disease and to maintain body weight), increases longevity, and promotes healthy living [4].

The relationship between HIV and undernutrition is bidirectional. Both are related each other in causing progressive damage to the immune system. HIV compromises nutritional status and poor nutrition further weakness the immune system of individuals.. The effect of malnutrition by itself can reduce the cluster of differentiation-four (CD4+) T cells and lead to abnormal B-cell response. For HIV infected patients, poor nutrition aggravates the effect of HIV by further decreasing the immune system $[3,5]$, thereby leading in undernutrition, increasing the risk of morbidity and mortality, and potentially reducing the efficacy of antiretroviral therapy (ART) [6].

Besides, HIV/AIDS patients often do not take enough food because of the illness and the ART medications decrease the appetite, change the taste of food and prevent the body from absorbing it. Similarly, the disease associatedconditions such as sore of the mouth, nausea, and vomiting make it challenge to eat [7]. A well-nourished people with HIV and who have a controlled viral load are more likely to be able to withstand the effect of HIV infection, supporting immune status and possibly delaying the progression of the disease [8]. Adequate nutrition is necessary for HIV infected patients to manage opportunistic infections, optimize response to medical treatment, keep up the immune system, and to support the ideal quality of life [2,9].

Malnourished HIV positive people experience lower survival rates, affect the overall clinical outcome and quality of life [10].

Undernutrition among HIV infected clients is often preventable, but recovering is difficult particularly those who are wasted, need more protein, and micronutrient intake to increase a weak-ended immune system.

[11]. Antiretroviral therapy (ART) was thought to be a solution to HIV-associated undernutrition. It is well established that most of clinically undernourished people living with HIV who start ART will improve or stabilize their weight [12]. As HIV infection progresses, it causes a catabolic state and increased susceptibility to infection which are compounded by lack of caloric and leading to progressive worsening of undernutrition. Thus, HIV viral load predicted weight loss and it appears that ART has made a reduction in the prevalence of undernutrition probably through the reduction in viral load. Because ART result in reduced viral replication, improved immunologic function and dramatic improvements in health, and prevents undernutrition $[2,13]$.

But, undernutrition remains a big issue for patients taking ART [14].

The prevalence of undernutrition among HIV-infected individuals was 19\% in Tanzania [15] and 10\% in Zimbabwe [16]. Ethiopia is also one of the countries hit hardest by the HIV epidemic alongside malnutrition [17]. The prevalence of undernutrition among HIV/AIDS patients receiving ART in Ethiopia ranges from 12.3 to $46.8 \%$ [18-24].

Different studies in different parts of the world revealed the factors associated with undernutrition were age, poor medication adherence, anemia, duration of the disease, opportunistic infection, advanced stage WHO, low CD4+ count, not taking co-trimoxazole, current substance use, marital status, residence, and active tuberculosis (TB) [18, 19, 21-25]. But the above factors are different across the studies. 
Besides remarkable efforts are made in increasing the treatment coverage of HIV/AIDS in the past decades, the high burden of HIV/AIDS and undernutrition has remained the major problems of health care systems in SSA [26].

Even though Ethiopia has significantly improved the treatment coverage of HIV/AIDS (71\%) in 2017 [27], HIV/AIDS prevalence remained high (0.9\%) [28]. Ethiopia is one among the 25 countries worldwide and 17 countries in Africa region with the highest number of new HIV infections [27]. HIV/AIDS and undernutrition combine to emasculate the immunity of many Ethiopians [29]. HIV related debilitating infections have severe nutritional consequences that commonly precipitate weight loss and finally lead to a wasting syndrome [30]. The high rates of undernutrition in Ethiopia worsens the impact of HIV and pose significant challenges to HIV care and treatment programs [31]. This calls for attention in improving the treatment effectiveness of existing HIV/AIDS services and one of the focus area of this actions was strengthening the nutritional assessment HIV/AIDS patients [20].

Continued study of the relationship between malnutrition and ART is important in low-income countries like Ethiopia, where many HIV/AIDS patients lack access to sufficient quantities of nutritious foods, which poses additional challenges to the success of ART $[2,6]$. New information concerning the burden of undernutrition among HIV positive patients is very important to provide quality care. Despite this fact, there was a limited study indicated the burden of undernutrition and associated factors among HIV infected patients in Eastern Zone in particular and in Tigray region in general. Hence, this study aimed to assess the prevalence of undernutrition and associated factors among adult HIV/AIADS patients receiving ART in Eastern Zone of Tigray, Northern Ethiopia.

\section{Methods}

\section{Study area, design, and period}

The study was conducted in public health facilities of Eastern Zone, which is found in Tigray region, Ethiopia. Eastern Zone is located in the Northern part of Ethiopia, which is $888 \mathrm{~km}$ away from the capital City Addis Ababa. Based on the 2007 census conducted by central static agency of Ethiopia, this Zone has a total population of 755,343 [32]. There are seven primaries and two general hospitals that provide ART services in Eastern Zone Tigray [33]. Out of these, three primaries and the two general hospitals were selected randomly. The study hospitals were Adigrat general hospital, Wukro general hospital, Atsbi primary hospital, Hawzen primary hospital, and Fatsi primary hospital.

The research study was an institutional-based as it employed cross-sectional research design conducted from April to May for two consecutive months in 2019.

\section{Population}

The study population were people living with HIV/AIDS that has been enrolled for ART follow-up service within the age cohort of greater than or equal to 18 years old as they are currently receiving ART treatment.

However, study respondents who are pregnant women, lactating mothers (6 months of postpartum), patients with edema like in congestive heart failure and ascites, and critically ill and/or patients with spinal deformity were excluded.

\section{Sample size determination and sampling technique}

The required sample size was determined using single population proportion formula taking 36.8\% 0.37 prevalence of undernutrition among adults with HIV/AIDS on ART with $5 \%$ of margin error and $95 \%$ confidence interval (CI) [20]. By adding $10 \%$ of non-response rate, the final sample size was determined as 394 . To select the required sample size the total sample size was proportionally allocated to the five public hospitals. Accordingly, the list of the patients were taken from the follow-up unit of the five public hospitals, and the sampling frame was developed. Then the first study subject was randomly selected from the sampling frame by using the lottery method and those participants were selected using a systematic sampling technique from the sampling frame.

\section{Data collection instruments and procedures}

Data were gathered using a structured and intervieweradministered questionnaire with the chart/document review (Additional file 2). The questionnaire consisted of four parts. Part I: Sociodemographic characteristics (gender, age, marital status, educational level, occupation, residence, and average house hold monthly income). Part II: Lifestyle/behavioral characteristics such as alcohol consumption, khat chewing and smoking status. Part III: ART medication adherence. Part IV: Chart/document review used to extract information related to HIV related characteristics, including immunological status and clinical characteristics (world health organization clinical stage, CD4 count, functional status, and opportunistic infections). The anemia status of the participants was ascertained using the standard criteria for female and male adults. Accordingly, patients were graded anemic when the hemoglobin concentration was less than $12.0 \mathrm{~g} / \mathrm{dl}$ and less than $13.0 \mathrm{~g} / \mathrm{dl}$ for females and males respectively.

Anthropometric measurement was carried out to determine the nutritional status of the study participants' by using Body Mass Index (BMI). The weight of the study subjects was measured using a beam balance to the nearest 0.1 $\mathrm{Kg}$ and measuring range up to $160 \mathrm{Kg}$. Weight was measured with light clothing and no shoes. Calibration was performed before weighing each participant by setting it to zero. Weighing scale also checked against a standard weight for its accuracy on a daily basis. The height of the 
respondents was measured using a vertical height scale standing upright in the middle of the board and recorded to the nearest $0.5 \mathrm{~cm}$. Respondents were asked to take off their shoes, stand erect, and look straight in the horizontal plane. The occiput, shoulder, buttocks, and heels touched measuring board and height was recorded to the nearest $0.01 \mathrm{~cm}$ [34]. Then BMI was computed by dividing weight in $\mathrm{kg}$ by the square of the height in meters $(\mathrm{kg} / \mathrm{m} 2)$. Accordingly, the study participants were classified as undernourished (underweight) if their BMI was less than $18.5 \mathrm{~kg} / \mathrm{m} 2$.

To maintain consistency, the questionnaire was first prepared in English then translated to the local language (Tigrigna) and was back-translated to English by professional translators. Five individuals who have completed their BSC in nursing education from a recognized University were recruited as data collectors. Another two senior BSC holder health officers who have experience in data collection were assigned as supervisors to check for the daily activity, consistency, and completeness of the questionnaire and to give appropriate support during the data collection process.

\section{Data processing and analysis}

The collected data were entered and analyzed using SPSS version 22. Both bivariate and multivariable logistic regression analysis were used to examine the association between each independent variable and dependent variable. The bivariate analysis is used to filter the important predictors. For that purpose, we have used a cut point of $p$ value $<0.25$ significance level in the bivariate logistic regression to transfer variables to multivariate analysis. The role of multivariate logistic regression was to determine statistical significance of the independent variables with the outcome variable and to show the strength of association between a set of independent variables and the outcome variable. The $p$-value $<0.05$ was used to test for association to show statistical significance in the multivariate logistic regression while the odds ratio (OR) was estimated at 95\% CI to show the strength of association.

Finally, text and tables were used to describe the results.

\section{Definition of variables}

Medication adherence was assessed using Morisky medication adherence score to ART medications having eight questions each with yes $=1$ and no $=0$, good adherence if they score $7-8$, and poor adherence if they score $\leq 6$ [35].

Alcoholic - a person who drinks 10.5 units of alcohol and above per week [36].

\section{Results}

Socio-demographic characteristics of respondents A total of 394 HIV positive patients were included. Of these, $249(63.2 \%)$ of the patients were females. The mean age $( \pm$ SD) of the respondents was 41 ( \pm 10$)$.
Table 1 Socio-demographic characteristics of HIV-infected patients in Eastern Zone Tigray, Ethiopia, 2019

\begin{tabular}{|c|c|c|c|}
\hline Variables & Category & Frequency & Percentage \\
\hline \multirow[t]{2}{*}{ Gender } & Male & 145 & 36.8 \\
\hline & Female & 249 & 63.2 \\
\hline \multirow[t]{4}{*}{ Age } & $18-24$ & 23 & 5.8 \\
\hline & $25-34$ & 64 & 16.2 \\
\hline & $35-44$ & 157 & 39.8 \\
\hline & $\geq 45$ & 150 & 38.1 \\
\hline \multirow[t]{4}{*}{ Marital status } & Married & 126 & 32 \\
\hline & Single & 81 & 20.6 \\
\hline & Divorced & 106 & 26.9 \\
\hline & Widowed & 81 & 20.6 \\
\hline \multirow[t]{5}{*}{ Level of education } & Can't read and write & 194 & 49.2 \\
\hline & Can read and Write & 80 & 20.3 \\
\hline & Primary school & 69 & 17.5 \\
\hline & Secondary school & 36 & 9.1 \\
\hline & Diploma and above & 15 & 3.8 \\
\hline \multirow[t]{7}{*}{ Occupation } & Farmer & 139 & 35.3 \\
\hline & Housewife & 44 & 11.2 \\
\hline & Governmental employee & 35 & 8.9 \\
\hline & Daily worker & 49 & 12.4 \\
\hline & Merchant & 37 & 9.4 \\
\hline & No work & 83 & 21.1 \\
\hline & Other & 7 & 1.8 \\
\hline \multirow[t]{4}{*}{ Religion } & Orthodox & 381 & 96.7 \\
\hline & Muslim & 6 & 1.5 \\
\hline & Catholic & 6 & 1.5 \\
\hline & Other & 1 & 0.3 \\
\hline \multirow[t]{2}{*}{ Ethnicity } & Tigray & 392 & 99.5 \\
\hline & Amhara & 2 & 0.5 \\
\hline \multirow[t]{2}{*}{ Residence } & Urban & 207 & 52.5 \\
\hline & Rural & 187 & 47.5 \\
\hline \multirow[t]{2}{*}{ House owner } & No & 160 & 40.6 \\
\hline & Yes & 234 & 59.4 \\
\hline \multirow[t]{3}{*}{ Family size } & $\leq 3$ & 174 & 44.2 \\
\hline & $4-6$ & 196 & 49.7 \\
\hline & $>6$ & 24 & 6.1 \\
\hline \multirow[t]{4}{*}{ Monthly income } & $<193$ & 16 & 4.1 \\
\hline & $193-420$ & 77 & 19.5 \\
\hline & $421-1700$ & 200 & 50.8 \\
\hline & $>1700$ & 101 & 25.6 \\
\hline
\end{tabular}


Concerning the marital status of the study population, $126(32 \%)$ of the respondents were married. On the other hand, $207(52.5 \%)$ of the respondents were living in urban areas (Table 1).

Nutritional status, clinical, behavioral, and immunological characteristics of respondents

Prevalence of undernutrition (BMI $\left.\leq 18.5 \mathrm{~kg} / \mathrm{m}^{2}\right)$ was $42.9 \%$. Of those, 26.6 and $16.2 \%$ of the study subjects had moderate (BMI $16-18.5 \mathrm{~kg} / \mathrm{m}^{2}$ ) and severe $(\mathrm{BMI}<$ $16 \mathrm{~kg} / \mathrm{m} 2)$ malnutrition respectively. Concerning medication adherence, about 365(92.6\%) of participants had poor adherence to the ART medication. The clinical condition of the participants at ART initiation indicated that about 205(52\%) had an opportunistic infection. Most patients started ART with advanced disease. For instance, 257(65.2\%) of the study participants had baseline clinical stage II and above. On the other hand, $55(14 \%)$ of the respondents did not use ionized preventive prophylaxis (IPT) (Table 2).

\section{Bivariate and multivariable logistic regression for factors associated with undernutrition among ART initiated HIV/ AIDS patients}

In this study, both bivariate and multivariable logistic regression analysis were computed. In the bivariate logistic regression, marital status, educational level, family size, $\mathrm{CD} 4+$ count, WHO clinical staging, active TB, co-

Table 2 Behavioral, clinical, and nutritional status of HIV-infected patients in Eastern zone of Tigray, Ethiopia, 2019

\begin{tabular}{|c|c|c|c|}
\hline Variables & Category & Frequency & percentage \\
\hline \multirow[t]{2}{*}{ Khat chewing status } & No & 384 & 97.5 \\
\hline & Yes & 10 & 2.5 \\
\hline \multirow[t]{2}{*}{ History of smoking } & No & 380 & 96.4 \\
\hline & Yes & 14 & 3.6 \\
\hline \multirow[t]{2}{*}{ Alcohol consumption } & No & 327 & 83 \\
\hline & Yes & 67 & 17 \\
\hline \multirow[t]{2}{*}{ Undernutrition } & Yes & 169 & 42.9 \\
\hline & No & 225 & 57.1 \\
\hline \multirow[t]{2}{*}{ Medication adherence } & poor & 365 & 92.6 \\
\hline & Good & 29 & 7.4 \\
\hline \multirow[t]{2}{*}{ TB status } & No & 270 & 68.5 \\
\hline & Yes & 124 & 31.5 \\
\hline \multirow[t]{3}{*}{ Functional status } & Working & 255 & 64.7 \\
\hline & Ambulatory & 77 & 19.5 \\
\hline & Bedridden & 62 & 15.7 \\
\hline \multirow[t]{2}{*}{ Opportunistic infection } & No & 189 & 48 \\
\hline & Yes & 205 & 52 \\
\hline \multirow[t]{4}{*}{ CD4+ count (cells/ul) } & $<200$ & 92 & 23.4 \\
\hline & $200-350$ & 66 & 16.8 \\
\hline & $351-500$ & 87 & 22.1 \\
\hline & $>500$ & 146 & 37.8 \\
\hline \multirow[t]{2}{*}{ Anemia } & Yes & 169 & 42.9 \\
\hline & No & 225 & 57.1 \\
\hline \multirow[t]{2}{*}{ WHO clinical stage } & Stage I & 137 & 34.8 \\
\hline & stage II and above & 257 & 65.2 \\
\hline \multirow[t]{2}{*}{ IPT prophylaxis } & No & 55 & 14 \\
\hline & Yes & 339 & 86 \\
\hline \multirow[t]{2}{*}{ Co-tromoxazole Prophylaxis } & No & 58 & 14.7 \\
\hline & Yes & 336 & 85.3 \\
\hline \multirow[t]{2}{*}{ Duration of HIV/AIDS } & $<2$ years & 13 & 3.3 \\
\hline & $\geq 2$ Years & 381 & 96.7 \\
\hline
\end{tabular}


trimoxazole therapy, and functional status were identified as candidate variables for multivariable logistic regression analysis. Out of those, only three variables were significantly associated with undernutrition. Therefore, participants with CD4+ count $<200$ cells $/ \mu$ l $(\mathrm{AOR}=1.84 ; 95 \%$ CI: 1-3.36), WHO clinical stage II and above (AOR = 3.6; 95\% CI: 2.11-6.18), and not taking co-trimoxazole prophylaxis ( $\mathrm{AOR}=2.38 ; 95 \% \mathrm{CI}: 1.21-4.67)$ were more likely to be at risk to develop undernutrition (Table 3).

\section{Discussion}

This study is focused on assessing the prevalence of undernutrition and associated factors among HIV infected patients after the initiation of ART. The overall prevalence of undernutrition was $42.9 \%$ (95\% CI, 37.8-47.7). This result is in line with other institutional-based studies conducted in Ethiopia such as Humora hospital (42.3\%) [37] and Jima University specialized hospital $(46.8 \%)$ [24]. But this is higher than other studies done

Table 3 Bivariate and multivariable analysis of factors associated with undernutrition in Eastern Zone, Tigray, Ethiopia, 2019

\begin{tabular}{|c|c|c|c|c|}
\hline \multirow{3}{*}{ Variables } & \multicolumn{2}{|c|}{ Undernutrition } & \multirow{3}{*}{ COR $(95 \% \mathrm{Cl})$} & \multirow{3}{*}{ AOR $(95 \% \mathrm{Cl})$} \\
\hline & Yes & No & & \\
\hline & $\mathrm{N}^{\circ}(\%)$ & № (\%) & & \\
\hline \multicolumn{5}{|l|}{ Marital status } \\
\hline Married & $56(33.1)$ & $70(31.1)$ & 1 & 1 \\
\hline Single & $30(17.8)$ & $51(22.7)$ & $1.36(.768-2.41)$ & $1.101(.58-2.09)$ \\
\hline Divorced & $53(31.4)$ & $53(23.6)$ & $0.8(.477-1.343)$ & $.88(.488-1.587)$ \\
\hline Widowed & $30(17.8)$ & $51(22.7)$ & $1.36(.768-2.41)$ & $1.14(.585-2.221)$ \\
\hline \multicolumn{5}{|l|}{ Educational level } \\
\hline Cannot read and write & $76(45)$ & $118(52.4)$ & 1.774(.618-5.094) & $.94(.293-3.037)$ \\
\hline Can read and write & $26(15.4)$ & $54(24)$ & $2.37(.777-7.254)$ & $1.68(.5-5.64)$ \\
\hline Primary school & $34(20.1)$ & 35 (15.6) & $1.17(.384-3.60)$ & $.895(.265-3.015)$ \\
\hline Secondary school & $25(14.8)$ & $11(4.9)$ & $0.50(.146-1.734)$ & $.43(.114-1.636)$ \\
\hline Diploma and above & $8(4.7)$ & $7(3.1)$ & 1 & 1 \\
\hline \multicolumn{5}{|l|}{ Family size } \\
\hline$\leq 3$ & $86(50.9)$ & $88(39.1)$ & 1 & 1 \\
\hline $4-6$ & $73(43.2)$ & $123(54.7)$ & 1.647 (1.087-2.493) & $1.21(.75-1.95)$ \\
\hline$>6$ & $10(5.9)$ & $14(6.2)$ & $1.368(.577-3.247)$ & 1.23(.47-3.22) \\
\hline \multicolumn{5}{|l|}{ CD4+ cells/ $\mu$ l counts } \\
\hline$<200$ & $31(18.3)$ & $61(27.1)$ & $2.221(1.296-3.807)$ & $1.84(1-3.36)^{*}$ \\
\hline $200-350$ & $24(14.2)$ & $42(18.7)$ & $1.975(1.088-3.584)$ & 1.53(.79-2.95) \\
\hline $351-500$ & $35(20.7)$ & $52(23.1)$ & $1.677(.981-2.865)$ & $1.5(.83-2.70)$ \\
\hline$>500$ & $79(46.7)$ & $70(31.1)$ & 1 & 1 \\
\hline \multicolumn{5}{|l|}{ WHO Clinical staging } \\
\hline Stage I & $87(51.5)$ & $50(22.2)$ & 1 & 1 \\
\hline Stage II and above & $82(48.5)$ & $175(77.8)$ & $3.713(2.4-5.74)$ & $3.6(2.11-6.18)^{*}$ \\
\hline \multicolumn{5}{|l|}{ Active TB status } \\
\hline No & $122(72.2)$ & $148(65.8)$ & 1 & 1 \\
\hline Yes & $47(27.8)$ & $77(34.2)$ & $1.35(.874-2.086)$ & $.66(.39-1.1)$ \\
\hline \multicolumn{5}{|l|}{ Co-trimoxazole } \\
\hline No & $17(10.1)$ & $41(18.2)$ & $1.992(1.1-3.65)$ & $2.38(1.21-4.67)^{*}$ \\
\hline Yes & $152(89.9)$ & $184(81.8)$ & 1 & 1 \\
\hline \multicolumn{5}{|l|}{ Functional status } \\
\hline Working & 99 (58.6) & $156(69.3)$ & 1 & 1 \\
\hline Ambulatory & $36(21.3)$ & $41(18.2)$ & $.723(.432-1.208)$ & 1.08(.56-2.07) \\
\hline Bedridden & $34(20.1)$ & $28(12.4)$ & $.523(.299-.915)$ & $.87(.43-1.76)$ \\
\hline
\end{tabular}


in Tanzania (19\%) [15] and Zimbabwe (10\%) [16]. Similarly, it is also higher than other studies done in Ethiopia such as in Arba Minch Town (23.2\%) [21], 12.3\% in Dilla University [19], and 23.2\% in Dembia district [23].

This different result among different studies could be explained by the discrepancy in health care awareness of the community and the sample size difference. Or it could be due to the difference in socio-economic and feeding styles of different ethnic groups of the country. Besides, it might be due to the difference and improvements in healthcare services. Or it might be as a result of the patients reporting with advanced stage of HIV infection to medical facilities.

This study indicated that CD4+-T cell count had a strong positive association with nutritional status. Participants with $\mathrm{CD} 4+<200 \mathrm{cell} / \mu \mathrm{l}$ had 1.84 times chance of being undernourished compared to those with $\mathrm{CD} 4+$ cells $/ \mu$ l count $>500(\mathrm{AOR}=1.84 ; 95 \% \mathrm{CI}$ : 1-3.36). Other studies done in Ethiopia [19, 21, 23, 24] showed similar associations. This result is also in line with other studies done in developed and developing countries [10, 38-40]. This relation is explained by the association of a low CD4 cell count with more advanced stages of infection, implying a higher frequency of opportunistic infections, which affect nutritional status by increasing metabolism and diminishing food intake because of factors such as fever, oral and esophageal lesions, anorexia and diarrhea [41].

Participants with world health organization clinical stage II and above were found 3.6 times more likelihood of being undernourished compared to those with WHO clinical stage I (AOR $=3.6$; 95\% CI: 2.11-6.18). This is also comparable with other studies that showed similar results in Ethiopia [19, 21, 22, 24]. This might be because patients with advanced disease stages are more susceptible to develop comorbid conditions. Thus, additional management of such comorbid conditions and the regular ART treatment worsen the side effects like loss of appetite and poor nutritional status of the patient, which compromise their resistance to the disease.

The initiation of co-trimoxazole preventive therapy at the start of ART was associated with the nutritional status of the participants. Based on this study, the odds of developing undernutrition among patients receiving ART who did not start co-trimoxazole preventive therapy were 2.38 times more likely to develop undernutrition compared to those who were started co-trimoxazole preventive therapy (AOR $=2.38$; 95\% CI: $1.21-4.67)$. The finding of this research is consistent with the studies conducted in Nigeria [42] and public health facilities of Arba Minch Town [21]. This similarity might be due to the fact antimicrobial effect of co-trimoxazole on bacterial disease and other opportunistic infections can help to improve the overall status of the patients.

\section{Limitations of the study}

The cross-sectional nature of the study limits the investigation to the level of the association between determinants and outcomes of interest (undernutrition). On the other hand, not using comprehensive anthropometric measurement tools like hip circumference limits this study because, only using BMI may not the exact measurement of malnutrition.

\section{Conclusion}

The result of this study indicated that the prevalence of undernutrition was high. Furthermore, being an advanced clinical staging, having a low CD4+ count, and not taking co-trimoxazole preventive therapy was positively associated with undernutrition. Therefore, the implementation of nutrition programs for patients living with HIV is crucial. Especially, the intervention must be focused for those patients who have advanced clinical stage of $\mathrm{CD} 4+$ count less than 200 cells/ul. Also, the emphasis must be considered for patients to undergo co-trimoxazole preventive therapy. Moreover, effort should be taken by governmental and nongovernmental stakeholders to improve the nutritional status of patients under ART to increase treatment effectiveness.

\section{Supplementary information}

Supplementary information accompanies this paper at https://doi.org/10. 1186/s13690-020-00486-z.

Additional file 1. S1 dataset- SPSS data of the questionnaire results. Additional file 2. S1 Appendix-English and Tigrigna version of the questionnaire.

\section{Abbreviations \\ AIDS: Acquired immune Deficiency Syndrome; AOR: Adjusted Odds Ratio; ART: Antiretroviral Therapy; BMI: Body Mass Index; COR: Crude Odds Ratio; Cl: Confidence Interval; HIV: Human immunodeficiency Virus; IPT: Isoniazid preventive therapy; WHO: World Health Organization; SPSS: Statistical Package for Social Science}

\section{Acknowledgments}

Our special appreciation goes to Adigrat University for the priceless support in the accomplishment of this project. The authors are thankful to the study respondents for giving their consent to participate in this study. We are also grateful to thank all the research assistants for their cooperation in the data collection process.

\section{Authors' contributions}

THG: Has initiated the idea, carried out the study and provided the final version. HHM: Critically revised the paper and has contributed to the pre-test of the tool. KGK: Recruit research assistants and participates in reviewing the design. All authors read and approved the final manuscript.

\section{Funding}

This research work was funded by Adigrat University.

The funder had no role in the study design, data collection and analysis, preparation of the entire manuscript or the decision to publish this manuscript.

\section{Availability of data and materials}

The dataset used and/or analyzed during the current study is included with in the article's additional file (Additional file 1). 


\section{Ethics approval and consent to participate}

Ethical clearance was obtained from Adigrat university research and community service directorate office. A letter of support was also issued from the Tigray Regional Health Office to each respective health institution. Besides, information about the study was provided and written informed consent was obtained from study participants to confirm their willingness to participate in the research study.

\section{Consent for publication}

Not applicable.

\section{Competing interests}

The authors declare that they have no competing interest.

Received: 31 August 2020 Accepted: 6 October 2020

Published online: 15 October 2020

\section{References}

1. UNIAS. UNAIDS data 2017media_asset/20170720_Data_book_2017_en.pdf. Available from: www.unaids.org/sites/default/files/; 2017.

2. Ivers LC, Cullen KA, Freedberg KA, Block S, Coates J, Webb P, et al. HIV/AIDS, undernutrition, and food insecurity. Clin Infect Dis. 2009;49(7):1096-102.

3. Fentie M, Wassie MM, Tesfahun A, Alemu K, Mequanent M, Ayele TA. Chronic energy deficiency and associated factors among adults living with HIV in Gondar University referral hospital Northwest Ethiopia. BMC Nutrition. 2017;3(1):11.

4. The vicious cycle of malnutrition and HIV. 2020. Available from: https:// www.researchgate.net/figure/The-vicious-cycle-of-malnutrition-and-HIV.

5. Duggal S, Chugh TD, Duggal AK. HIV and malnutrition: effects on immune system. Clin Dev Immunol. 2012;2012:784740.

6. Benzekri NA, Sambou J, Diaw B, Sall EHI, Sall F, Niang A, et al. High prevalence of severe food insecurity and malnutrition among HIV-infected adults in Senegal, West Africa. PLoS One. 2015;10(11):e0141819.

7. Tsitsi P, Mercy K. Research article A choice to remain Healthy: an analysis of diet and nutrition of people living with HIV/AIDS in gweru Urban. Scholars Acad J Biosci. 2014;2(7):410-8.

8. Control, C.f.D. and Prevention. A manual: measuring and interpreting malnutrition and mortality. Rome: World Food Programme; 2005. p. 20.

9. Gebremichael DY, Hadush KT, Kebede EM, Zegeye RT. Food insecurity, nutritional status, and factors associated with malnutrition among people living with HIV/AIDS attending antiretroviral therapy at public health facilities in west Shewa zone, Central Ethiopia. Biomed Res Int. 2018;2018:1913534.

10. Johannessen A, Naman E, Ngowi BJ, Sandvik L, Matee Ml, Aglen HE, et al. Predictors of mortality in HIV-infected patients starting antiretroviral therapy in a rural hospital in Tanzania. BMC Infect Dis. 2008;8(1):52.

11. Kalofonos IA. "All I eat is ARVs": the paradox of AIDS treatment interventions in Central Mozambique. Med Anthropol Q. 2010;24(3):363-80.

12. Ivers LC, Kendrick D, Doucette K. Efficacy of antiretroviral therapy programs in resource-poor settings: a meta-analysis of the published literature. Clin Infect Dis. 2005;41(2):217-24.

13. Organization, W.H. Nutritional considerations in the use of ART in resourcelimited settings; 2005.

14. Wanke CA, Silva M, Knox TA, Forrester J, Speigelman D, Gorbach SL. Weight loss and wasting remain common complications in individuals infected with human immunodeficiency virus in the era of highly active antiretroviral therapy. Clin Infect Dis. 2000;31(3):803-5.

15. Kabalimu TK, Sungwa E, Lwabukuna WC. Malnutrition and associated factors among adults starting on antiretroviral therapy at PASADA Hospital in Temeke District, Tanzania. Tanzan J Health Res. 2018;20(2)..

16. Takarinda KC, et al. Malnutrition status and associated factors among HIV-positive patients enrolled in ART clinics in Zimbabwe. BMC Nutrition. 2017;3(1):15.

17. Bank W. HIV/AIDS, nutrition and food security: what we can do. A synthesis of international guidance; 2013.

18. Gedle D, Gelaw B, Muluye D, Mesele M. Prevalence of malnutrition and its associated factors among adult people living with HIV/AIDS receiving antiretroviral therapy at Butajira hospital, southern Ethiopia. BMC Nutrition. 2015;1(1):5.

19. Hailemariam S, Bune GT, Ayele HT. Malnutrition: prevalence and its associated factors in people living with HIV/AIDS, in Dilla University referral hospital. Arch Publ Health. 2013;71(1):13

20. Daka DW, Ergiba MS. Prevalence of malnutrition and associated factors among adult patients on antiretroviral therapy follow-up care in Jimma Medical Center, Southwest Ethiopia. PloS one. 2020;15(3):e0229883.
21. Oumer B, Boti N, Hussen S, Gultie T. Prevalence of under nutrition and associated factors among adults receiving first-line antiretroviral treatment in public health facilities of Arba Minch town, southern Ethiopia. HIV/AIDS (Auckland, NZ). 2019;11:313.

22. Ayalew GTAT. Prevalence of malnutrition and its associated factors among adult HIV positive clients on anti-retroviral therapy at Chiro zonal hospital, west Hararghe Oromia zone, Ethiopia; 2020. Available from: https://www. hilarispublisher.com/open-access/prevalence-of-malnutrition-and-its-assoc.

23. Mitiku A, Ayele TA, Assefa M, Tariku A. Undernutrition and associated factors among adults living with human immune deficiency virus in Dembia District, Northwest Ethiopia: an institution based cross-sectional study. Arch Publ Health. 2016;74(1):33.

24. Mulu H, Hamza L, Alemseged F. Prevalence of malnutrition and associated factors among hospitalized patients with acquired immunodeficiency syndrome in Jimma University specialized hospital, Ethiopia. Ethiop J Health Sci. 2016;26(3):217-26

25. Negessie A, Jara D, Taddele M, Burrowes S. Determinants of undernutrition among adult patients receiving antiretroviral therapy at Debre Markos referral hospital, Northwest Ethiopia: a case-control study design. BMC Nutrition. 2019:5(1):20.

26. GLOBAL HIV STATISTICS. Global AIDS Update 2019. 2019.. UNAIDS.

27. Office, F.H.A.P.a.C HIV prevention in Ethiopia. National Road map (20182020); 2018

28. Demographic CE. Health Survey-2011. Maryland: Central Statistical Agency Addis Ababa. Ethiopia ICF International Calverton; 2012. p. 2016.

29. Ethiopia, T.f.m.o National guidelines for HIV/AIDS and nutrition in Ethiopia; 2008.

30. Organization, W.H. Diet, nutrition, and the prevention of chronic diseases: report of a joint WHO/FAO expert consultation. Vol. 916: World Health Organization of the food and agriculture organization of the Unite Nations; 2003.

31. Ethiopia Nutrition and HIV Tools: Food and nutrition. The federal democratic of Ethiopia, Ministry of health National Nutrition and HIV/AIDS Implementation Reference Manual. In: Ministry of health Ethiopia: Food and Nutrition Technical assistance publications; 2008

32. Central statistical agency of Ethiopia "C.S.A.o.E. Mibragawi Zone Census 2007; 2020. Available from: https://en.wikipedia.org/wiki/Mibraqawi_Zone.

33. Tigray Regional Health Bureau. Ten years health bulletin (Ethiopia fiseal year 1998-2007); 2018.

34. World health organization. Physical status: the use of and interpretation of anthropometry, report of a WHO expert committee; 1995.

35. Morisky DE. Predictive validity of a medication adherence measure in an outpatient setting. J Clin Hypertens. 2008;10(5):348-54

36. FMHACA. Standard Treatment Guidlines for General hospital. Addis Ababa: Food, Medicine and Healthcare Administration and Control Authority of Ethiopia; 2014.

37. Hadgu TH, Worku W, Tetemke D, Berhe H. Undernutrition among HIV positive women in Humera hospital, Tigray, Ethiopia, 2013: antiretroviral therapy alone is not enough, cross sectional study. BMC Public Health. 2013; 13(1):943.

38. The Federal Democratic Republic of Ethiopia. Ministry of Health National Nutrition and HIV/AIDS implementation reference manual, Ministry of Health; 2008.

39. Mehta SH, Astemborski J, Sterling TR, Thomas DL, Vlahov D. Serum albumin as a prognostic indicator for HIV disease progression. AIDS Res Human Retroviruses. 2006;22(1):14-21.

40. Evans D, Maskew M, Sanne I. Increased risk of mortality and loss to followup among HIV-positive patients with oropharyngeal candidiasis and malnutrition before antiretroviral therapy initiation: a retrospective analysis from a large urban cohort in Johannesburg, South Africa. Oral Surg Oral Med Oral Pathol Oral Radiol. 2012;113(3):362-72.

41. Santos ACOD, Almeida AMR. Nutritional status and CD4 cell counts in patients with HIV/AIDS receiving antiretroviral therapy. Rev Soc Bras Med Trop. 2013;46(6):698-703

42. Denue BA. Knowledge regarding co-trimoxazole preventive therapy among patients who are HIV positive in a tertiary health facility, northeastern Nigeria. Sub-Saharan Afr J Med. 2017:4(2):31.

\section{Publisher's Note}

Springer Nature remains neutral with regard to jurisdictional claims in published maps and institutional affiliations. 